\title{
Electronic nicotine delivery system (ENDS) liquid nicotine exposure in young children presenting to US emergency departments, 2018
}

Joanne T. Chang ${ }^{*}$ (I) and Brian L. Rostron

\begin{abstract}
Background: Increased use of electronic nicotine delivery systems (ENDS) in the United States (U.S.) has been related to acute adverse events from liquid nicotine exposure. Previous studies have reported on these events through 2017.

Findings: We used 2018 National Emergency Injury Surveillance System data to generate national estimates with 95\% confidence intervals (Cls) of ENDS liquid nicotine-related poisonings among children under age 5 treated in U.S. hospital emergency departments (EDs). In 2018, an estimated 885 (95\% Cl: 397-1374) poisoning cases related to liquid nicotine among children under 5 were treated in U.S. EDs, which was a non-statistically signficant increase from 2017 (411 poisoning cases, 95\% Cl: 84-738). The most common route of exposure was through ingestion (99.4\%). The majority of cases were treated and released from the hospital (90.0\%), 8.9\% of the cases left the hospital without being seen, and $1.1 \%$ of the cases were treated and admitted to the hospital.

Conclusions: This study provides updated national estimates of poisoning events related to liquid nicotine exposure that occurred in 2018 among children under age 5. Updated information from this study may complement public education efforts and prevent liquid nicotine exposure among children.
\end{abstract}

Keywords: ENDS, E-cigarettes, NEISS, CPSC, E-liquid, FDA, Liquid nicotine poisoning

\section{Background}

Electronic cigarettes (e-cigarettes) are battery-operated electronic nicotine delivery systems (ENDS) that use "e-liquid" that may contain nicotine and other additives that are heated and inhaled by users in aerosol form (US Food and Drug Administration n.d.-a). In 2018, an estimated 3.05 million high school students (20.8\%) and 570,000 middle school students (4.9\%) in the United States (U.S.) reported using ENDS in the past 30 days (Cullen et al. 2018); in 2017, an estimated 6.9 million U.S. adults (2.8\%) were current ENDS users (Wang et al. 2018).

The increased use of ENDS has generated discussions about their potential risks and benefits for population

\footnotetext{
* Correspondence: joanne.chang@fda.hhs.gov

Center for Tobacco Products, Office of Science, Document Control Center, US Food and Drug Administration, Building 71, Room G335, 10903 New Hampshire Avenue, Silver Spring, MD 20993-0002, USA
}

health. The unintentional exposure of liquid nicotine among children under 5 could lead to potential harm to neurological development, cause symptoms that require medical care, and result in death (Eggleston et al. 2016; Morley et al. 2017). Our previous study (Chang et al. 2019) using National Electronic Injury Surveillance System (NEISS) data estimated that 4745 liquid nicotine poisoning cases in children under age 5 presented to U.S. hospital emergency departments (EDs) from 2013 to 2017. Additionally, other studies have used data from the National Poison Data System (NPDS) to evaluate ENDS poisoning in young children (Chatham-Stephens et al. 2016; Govindarajan et al. 2018; Kamboj et al. 2016; Wang and Rostron 2017); however, these studies were unable to calculate population estimates of ENDS liquid nicotine poisoning because NPDS is not nationally representative.

(c) The Author(s). 2019 Open Access This article is distributed under the terms of the Creative Commons Attribution 4.0 International License (http://creativecommons.org/licenses/by/4.0/), which permits unrestricted use, distribution, and 
In this study, we use NEISS data from 2018 to update national estimates of U.S. hospital ED visits for poisoning events related to ENDS liquid nicotine in children under age 5.

\section{Methods}

\section{Data source}

Detailed information on NEISS methods has been published elsewhere (US Consumer Product Safety Commission 2017). In brief, NEISS, maintained by the U.S. Consumer Product Safety Commission (CPSC), collects nonfatal injury data from about 100 U.S. hospitals with at least six beds that are selected as a nationally-representative probability sample of approximately 5000 U.S. hospital EDs (Schroeder and Adlt 2001). Each case in the NEISS database includes information on demographics, diagnosis, disposition, affected body part, product code, and a 142-character text narrative of the incident.

\section{Case extraction}

We have previously published a description of the approach used here (Chang et al. 2019). In brief, to identify ENDS liquid nicotine-related events, we conducted a text search of the NEISS data using the text narrative field, including the following keywords: "cig," "e-cig," "ENDS," "e-cigarettes, " "vapor," "vape," "e-hookah," "hookah-pen," "e-pipe," "juul, " "jew," "pods," "liquid," "nicotine," "juice," “e-liquids," and "eliquid." To identify poisoning-specific events, diagnosis code 68 ("poisoning") was used. Since the diagnosis code is not specific to liquid nicotine poisoning events, we reviewed the text narrative involving liquid nicotine cases and identified routes of exposure (ingestion, dermal, or ocular). We identified cases related to ingestion using keywords such as "drink," "drank," "ingest," "chew," "sip," "swallow," "suck," "mouth," and "tongue"; cases related to dermal exposure using keywords such as "skin" and "dermal"; and cases related to ocular exposure using keywords such as "eye" and "ocular." All cases were identified using the "FIND" procedure in the SAS program (version 9.4), and reviewers manually checked these cases were coded correctly.

In addition, two reviewers independently checked all extracted events and excluded events related to cigarette poisoning, or events not related to liquid nicotine exposure (Chang et al. 2019; Corey et al. 2018).

\section{Statistical analyses}

We calculated the weighted population estimates of poisoning using the PROC SURVEY procedure in SAS program, accounting for the sample weights and complex design. We then estimated the weighted distribution of these events by the following characteristics: age groups (younger than age 2 and ages 2-4), sex (male and female), race (White and other/not stated), disposition (treated and admitted, treated and released, and left without being seen), location (home, other locations, unspecified), and route of exposure (ingestion and other/ not stated).

CPSC considers the estimates to be unstable if (US Food and Drug Administration n.d.-a) the estimate is less than 1200 (Cullen et al. 2018); the number of records used is less than 20; or (Wang et al. 2018) the coefficient of variation is greater than 33\% (Schroeder and Adlt 2001).

\section{Results}

In 2018, we found 26 liquid nicotine poisoning cases in the NEISS database, representing an estimate of 885 (95\% CI: 397-1374) cases among children under 5 who were treated in U.S. hospital EDs (Table 1). Most injuries occurred among females (69.9\%), Whites (62.3\%), and those under age 2 (59.4\%). The most common route of exposure was through ingestion (99.4\%). The majority of cases were treated and released from the hospital (90.0\%), 8.9\% of the cases left the hospital without being seen, and $1.1 \%$ of the cases were treated and admitted to the hospital.

After examining the case narratives, we found that five out of 26 unweighted cases had information on symptoms, where 3 cases had vomiting, and 2 cases had emesis, and five cases had information on nicotine dose or concentration, where 2 cases ingested $60 \mathrm{~mL}, 1$ case ingested $10 \mathrm{~mL}$, and 2 cases ingested $0.6 \mathrm{mg}$ and 3 cotton filters, respectively. We found 21 cases reported the poisonings occurred at home.

\section{Discussion}

We used nationally representative data to update the estimate of ENDS liquid nicotine exposure among children under 5 and we found about 900 weighted cases occurred in 2018. From 2017 to 2018, we observed that liquid nicotine poisoning cases increased from 411 (Chang et al. 2019) to 885 . Previously, we documented a large drop in nicotine exposure cases from 2015 to 2017, coinciding with the implementation of the Child Nicotine Poisoning Prevention Act (CNPPA) (Frey and Tilburg 2016). Although this increase is non-statistically significant, this raises potential concerns regarding the effectiveness of existing regulations as well as public health education efforts to protect young children from accident liquid nicotine poisoning.

Our study has some limitations. First, our estimates do not represent cases not treated in EDs; thus, total cases are likely to be underestimated. Wang et al. (2019) (Wang et al. n.d.) have estimated that about 29\% of ENDS-related adverse events in NPDS resulted in EDs, and two-third occurred among children under 5. Additionally, the weighted estimate is less than 1200 , which CPSC considered a national estimate unstable and 
Table 1 Electronic nicotine delivery system (ENDS) liquid nicotine-related injuries treated in emergency departments in the United States in 2018 in children under age 5

\begin{tabular}{|c|c|c|}
\hline Characteristics & Unweighted N & $N(\%)$ \\
\hline All & 26 & 885 (95\% Cl: 397-1374) \\
\hline \multicolumn{3}{|l|}{ Age } \\
\hline Younger than age 2 years & 17 & $526(59.4)$ \\
\hline Ages $2-4$ years & 9 & $359(40.6)$ \\
\hline \multicolumn{3}{|l|}{ Sex } \\
\hline Male & 15 & $267(30.1)$ \\
\hline Female & 11 & $618(69.9)$ \\
\hline \multicolumn{3}{|l|}{ Race } \\
\hline White & 15 & $552(62.3)$ \\
\hline Other/not stated & 11 & $333(37.7)$ \\
\hline \multicolumn{3}{|l|}{ Disposition } \\
\hline Treated and admitted to a hospital & 2 & $10(1.1)$ \\
\hline Treated and released & 23 & $797(90.0)$ \\
\hline Left without being seen & 1 & $78(8.9)$ \\
\hline \multicolumn{3}{|l|}{ Location } \\
\hline Home & 21 & $847(95.7)$ \\
\hline Not stated & 5 & $38(4.3)$ \\
\hline \multicolumn{3}{|l|}{ Route of exposure } \\
\hline Ingestion & 25 & $880(99.4)$ \\
\hline Other/not stated & 1 & $5(0.56)$ \\
\hline
\end{tabular}

${ }^{a}$ CPSC considers the estimates to be unstable if (1) the estimate is less than 1200; (2) the number of records used is less than 20; or (3) the coefficient of variation is greater than $33 \%$

potentially unreliable. Second, because NEISS data do not include product codes specific to ENDS or injury symptoms, we had to use general keywords to capture these events, which may also underestimate the burden. Third, findings may not represent the rapidly changing ENDS marketplace. Fourth, three cases indicated "possible or unsure ingestion"; thus, it is unclear whether these children ingested liquid nicotine. Lastly, ENDS liquid nicotine poisoning cases can also occur in children older than age 5, but these cases were not captured in NEISS (US Consumer Product Safety Commission n.d.).

Despite these limitations, this study extends previous findings (Chang et al. 2019) by updating national estimates of the number of U.S. ED visits for poisonings related to liquid nicotine exposure among children under 5. Updated information from this study may complement public education efforts and prevent liquid nicotine exposure among children. The U.S. FDA asserted regulatory jurisdiction over all tobacco products including ENDS in 2016 (US Food and Drug Administration n.d.-b). As such FDA is actively investigating scientific issues that can inform regulatory activities related to ENDS. Continued surveillance of these short-term outcomes can inform regulatory and educational activities.

\section{Abbreviations}

CDC: Centers for Disease Control and Prevention; Cl: Confidence Interval; ED: Emergency Department; ENDS: Electronic Nicotine Delivery System; NEISS: National Electronic Injury Surveillance System; NPDS: National Poison Data System; U.S. CPSC: U.S. Consumer Product Safety Commission; U.S.: United States

Acknowledgements

We thank Deborah Neveleff for reviewing the manuscript.

\section{Disclaimer}

This publication represents the views of the authors and does not represent FDA/CTP position or policy.

\section{Authors' contributions}

JTC conceived the study concept, performed the statistical analysis, and drafted the manuscript. BLR contributed to the study concept and revised the manuscript. Both authors read and approved the final manuscript.

\section{Funding}

Funding for this study was provided by the Center for Tobacco Products, US Food and Drug Administration.

\section{Availability of data and materials}

We analyzed the 2018 NEISS public use data file available from CPSC's website under "Archived Full NEISS data by year" https://www.cpsc.gov/ Research\%2D-Statistics (last accessed 31 May 2019).

\section{Ethics approval and consent to participate}

Because only anonymized, publicly-available data were used, the study was considered exempt from human subjects committee review. 


\section{Consent for publication}

No applicable.

\section{Competing interests}

The authors declare that they have no competing interests.

Received: 5 August 2019 Accepted: 24 September 2019

Published online: 21 October 2019

\section{References}

Chang JT, Wang B, Chang CM, Ambrose BK. National estimates of poisoning events related to liquid nicotine in young children treated in US hospital emergency departments, 2013-2017. Inj Epidemiol. 2019;6(1):10. https://doi. org/10.1186/s40621-019-0188-9.

Chatham-Stephens K, Law R, Taylor E, et al. Exposure calls to U. S. Poison centers involving electronic cigarettes and conventional cigarettes-September 2010December 2014. J Med Toxicol. 2016;12(4):350-7. https://doi.org/10.1007/ s13181-016-0563-7.

Corey CG, Chang JT, Rostron BL. Electronic nicotine delivery system (ENDS) battery-related burns presenting to US emergency departments, 2016. Inj Epidemiol. 2018;5(1):4. https://doi.org/10.1186/540621-018-0135-1.

Cullen KA, Ambrose BK, Gentzke AS, Apelberg BJ, Jamal A, King BA. Notes from the Field: Use of Electronic Cigarettes and Any Tobacco Product Among Middle and High School Students - United States, 2011-2018. MMWR Morb Mortal Wkly Rep. 2018;67(45):1276-7. https://doi.org/10. 15585/mmwr.mm6745a5.

Eggleston W, Nacca N, Stork CM, Marraffa JM. Pediatric death after unintentional exposure to liquid nicotine for an electronic cigarette. Clin Toxicol (Phila). 2016;54(9):890-1. https://doi.org/10.1080/15563650.2016.1207081.

Frey LT, Tilburg WC. Child-resistant packaging for e-liquid: a review of US state legislation. Am J Public Health. 2016;106(2):266-8. https://doi.org/10.2105/ AJPH.2015.302957.

Govindarajan P, Spiller HA, Casavant MJ, Chounthirath T, Smith GA. E-Cigarette and liquid nicotine exposures among young children. Pediatrics. 2018;141(5). https://doi.org/10.1542/peds.2017-3361

Kamboj A, Spiller HA, Casavant MJ, Chounthirath T, Smith GA. Pediatric exposure to e-cigarettes, nicotine, and tobacco products in the United States. Pediatrics. 2016;137(6). https://doi.org/10.1542/peds.2016-0041.

Morley S, Slaughter J, Smith PR. Death from ingestion of E-liquid. J Emerg Med. 2017;53(6):862-4. https://doi.org/10.1016/j.jemermed.2017.06.029.

Schroeder T, Adlt K. NEISS sample design (design and implementation), 1997 to present; 2001.

US Consumer Product Safety Commission. NEISS Coding Manual 2017.

US Consumer Product Safety Commission. National Electronic Injury Surveillance System (NEISS). US Consumer Product Safety Commission https://www.cpsc. gov/Safety-Education/Safety-Guides/General-Information/National-ElectronicInjury-Surveillance-System-NEISS/ Accessed 8 Mar 2018.

US Food and Drug Administration. Vaporizers, e-cigarettes, and other electronic nicotine delivery systems (ENDS). US Food and Drug Administration https:// www.fda.gov/TobaccoProducts/Labeling/ProductsIngredientsComponents/ ucm456610.htm Accessed 8 Mar 2018.

US Food and Drug Administration. FDA's deeming regulations for e-Cigarettes, cigars, and all Other Tobacco Products US Food and Drug Administration https://www.fda.gov/tobacco-products/rules-regulations-and-guidance/fdasdeeming-regulations-e-cigarettes-cigars-and-all-other-tobacco-products Accessed 12 Sept 2019.

Wang B, Liu S, Persoskie A. Poisoning exposure cases involving e-cigarettes and e-liquid in the United States, 2010-2018. Clin Toxicol (Phila). 2019:1-7. https:// doi.org/10.1080/15563650.2019.1661426.

Wang B, Rostron B. Tobacco-related poison events involving young children in the US, 2001-2016. Tob Regul Sci. 2017;3(4):525-35. https://doi.org/10. 18001/trs.3.4.12.

Wang TW, Gentzke A, Sharapova S, Cullen KA, Ambrose BK, Jamal A. Tobacco Product Use Among Middle and High School Students - United States, 2011-2017. MMWR Morb Mortal Wkly Rep. 2018;67(22):629-33. https://doi. org/10.15585/mmwr.mm6722a3.

\section{Publisher's Note}

Springer Nature remains neutral with regard to jurisdictional claims in published maps and institutional affiliations.

\section{Ready to submit your research? Choose BMC and benefit from}

- fast, convenient online submission

- thorough peer review by experienced researchers in your field

- rapid publication on acceptance

- support for research data, including large and complex data types

- gold Open Access which fosters wider collaboration and increased citations

- maximum visibility for your research: over $100 \mathrm{M}$ website views per year

At BMC, research is always in progress.

Learn more biomedcentral.com/submissions 